\title{
Biochemical identification of clinically important yeasts
}

\author{
JOHN DE LOUVOIS, ANNE MULHALL, AND ROSALINDE HURLEY \\ From Queen Charlotte's Hospital for Women and The Institute of Obstetrics and Gynaecology, \\ University of London, $U K$
}

SUMMARY Four commercially available kits for the speciation of yeasts were tested against 50 clinical isolates that had been identified by conventional methods. On biochemical grounds alone, the four systems varied from $71 \%$ to $100 \%$ in their efficiency in identifying Candida albicans. Yeasts other than $C$. albicans were identified with an efficiency varying from $24 \%$ to $83 \%$. Conclusions are drawn on the value of these systems to the routine laboratory.

Although Candida albicans is the principal pathogen of the genus, a number of other Candida species cause disease in man (Hurley, 1967; van Uden and Buckley, 1970) as do yeasts of other genera (Gentles and La Touche, 1969). Since antifungal agents with a selective or narrow range of activity are available, it is important that speciation of yeasts in routine clinical microbiological practice should be effected rapidly and reliably. Conventional methods of identification (van der Walt, 1970) are cumbersome and often beyond the range of expertise available in non-specialist laboratories. Commercially available kits have been marketed to aid identification of pathogenic yeasts, and it is the purpose of this study to report results obtained with four of these, using the criteria of identification of Lodder (1970) as the reference system and basis of comparison.

\section{Material and methods}

\section{STRAINS STUDIED}

Fifty isolates from man were studied, 25 originating from patients of Queen Charlotte's Maternity Hospital and 25 kindly supplied by the Mycology Reference Laboratory.

The organisms were identified using auxanograms, zymograms, and other tests (Lodder, 1970).

\section{TEST KITS}

The kits tested were:

(a) API 20C, which consists of 19 fermentation and assimilation tests and a control presented as a strip

Received for publication 8 January 1979 of cupules and accompanied by an ampoule of suspending medium.

(b) API 20C (Auxanogramme), an improved version of $(a)$, in which all 19 reagent cupules contain substrates for assimilation.

(c) Mycotube (Roche), based on the principle of the Enterotube, an inoculated needle being drawn through eight agar-filled compartments. The first two compartments contain urea and citrate, followed by five carbohydrate substrates. There is the facility to observe gas production from glucose and sucrose. (d) Auxodisk (Sobioda), which consists of an eightpronged blotting paper disc containing carbon sources and actidione with glucose, which is applied to a seeded base medium free from utilisable carbon source. The tests contained in the four systems are shown in Table 1.

\section{Procedure}

Fresh cultures of the 50 isolates studied were made on Sabouraud's dextrose agar using a numerical system of identification, so that subsequent investigations were carried out 'blind'. Selected colonies were used to inoculate all four kits according to the manufacturers' instructions. The recommended times for incubation were: Auxodisk, 18-24 hours; API 20C, 48 hours; Mycotube and API 20C (Auxanogramme), 72 hours at $37^{\circ} \mathrm{C}$. After incubation the results were read from the identification tables accompanying each kit. API 20C, Mycotube, and Auxodisk had simple tables of reactions for the recognition of 27 , 13, and 9 species/groups of fungi respectively. The API 20C (Auxogramme) System is computer-based and contains information for the identification of 26 taxa. The reactions obtained are converted into 
Table 1 Reagents contained in the four systems tested

\begin{tabular}{|c|c|c|c|c|}
\hline & $A P I 20 C$ & $\begin{array}{l}\text { API } 20 C \\
\text { Auxano- } \\
\text { gramme }\end{array}$ & Auxodisk & Mycotube \\
\hline $\begin{array}{l}\text { Dextrose } \\
\text { Xylose } \\
\text { Sucrose } \\
\text { Raffinose } \\
\text { Lactose } \\
\text { Trehalose } \\
\text { Citrate } \\
\text { Urea } \\
\text { Maltose } \\
\text { Galactose } \\
\text { Celibiose } \\
\text { Actidione } \\
\text { Melibiose } \\
\text { Inositol } \\
\text { 2-keto-D-gluconate } \\
\text { Arabinose } \\
\text { Xylose } \\
\text { Adonitol } \\
\text { Xylitol } \\
\text { Glycine } \\
\text { Sorbitol } \\
\text { Methyl-D-glucoside } \\
\text { N-acetyl-D-glucosamine } \\
\text { Melizitose }\end{array}$ & $\begin{array}{l}+1+ \\
+1+ \\
+1+ \\
+1+ \\
+1+ \\
\\
+1+ \\
+1+ \\
-1+ \\
+ \\
+1+ \\
-1+ \\
\\
\end{array}$ & $\begin{array}{l}-1+ \\
-1+ \\
-1+ \\
-1+ \\
-1+ \\
\\
-1+ \\
-1+ \\
-1+ \\
\\
-1+ \\
-1+ \\
-1+ \\
-1+ \\
-1+ \\
-1+ \\
-1+ \\
-1+ \\
-1+ \\
-1+ \\
-1+\end{array}$ & $\begin{array}{l}+1- \\
+1- \\
+1- \\
+1-\end{array}$ & $\begin{array}{l}+1- \\
+1- \\
+1- \\
+1- \\
+1- \\
+1- \\
+ \\
+\end{array}$ \\
\hline
\end{tabular}

* Fermentation/Assimilation

a numerical profile, which is read from a profile index. All four systems had a shelf-life at $4^{\circ} \mathrm{C}$ of 12 months or longer.

\section{Results}

The original identity of the cultures was confirmed using the procedures described by Lodder (1970). The number of isolates studied and the number of correct identities obtained with each of the identification schemes are shown in Table 2. The three isolates grouped as Candida species (Table 2) were $C$. pulcherrima, C. claussenii, and $C$. pelliculosa, and the three species of Geotrichum were G. asteroides, $G$. matalense, and $G$. candidum. All four systems

Table 2 Number of yeasts correctly identified by the four schemes

\begin{tabular}{|c|c|c|c|c|c|}
\hline $\begin{array}{l}\text { Yeast } \\
\text { C. albicans }\end{array}$ & \multicolumn{4}{|c|}{$\begin{array}{c}\text { No. API 20C API 20C Auxodisk } \\
\text { Auxano- } \\
\text { gramme }\end{array}$} & $\begin{array}{l}\text { Mycotube } \\
15\end{array}$ \\
\hline $\begin{array}{l}\text { C. albicans } \\
\text { C. parapsilosis } \\
\text { C. tropicalis } \\
\text { C. pseudotropicalis } \\
\text { C. stellatoidea } \\
\text { Candida species } \\
\text { T. glabrata } \\
\text { S. cerevisiae } \\
\text { C. neoformans } \\
\text { Geotrichum species } \\
\text { Trichosporon cutaneum }\end{array}$ & $\begin{array}{r}21 \\
2 \\
2 \\
3 \\
2 \\
3 \\
7 \\
3 \\
3 \\
3 \\
1\end{array}$ & $\begin{array}{l}16 \\
2 \\
0 \\
3 \\
0 \\
0 \\
7 \\
3 \\
2^{*} \\
0 \\
1^{*}\end{array}$ & $\begin{array}{r}19 \\
2 \\
2 \\
2 \\
2 \\
0 \\
6 \\
3 \\
3 \\
3 \\
1\end{array}$ & $\begin{array}{l}21 \\
1 \\
2 \\
3 \\
0 \\
0 \\
0 \dagger \\
0 \dagger \\
0 \\
0 \\
0\end{array}$ & $\begin{array}{l}15 \\
0 \\
2 \\
3 \\
0 \\
0 \\
7 \\
3 \\
3^{*} \\
0 \\
0\end{array}$ \\
\hline
\end{tabular}

*Identity of best fit

†Species not listed were reasonably efficient at identifying $C$. albicans, API 20C (Auxanogramme) and Auxodisk being marginally better than the other two. The Auxodisk scheme does not include reactions for Torulopsis glabrata and, as a result, the seven isolates of this species would have been identified as $C$. krusei using biochemical results alone. The majority of Torulopsis were correctly identified by the other schemes. Only API 20C (Auxanogramme) identified satisfactorily the three isolates of Cryptococcus neoformans. Using Mycotube they would probably have been identified correctly by their positive urea reactions, although they were all citrate negative. Using Auxodisk, they were identified as $C$. tropicalis because of the absence of a positive reaction with cellibiose. Using API 20C, Auxodisk, and Mycotube, we were unable to identify species of Candida or Geotrichum infrequently isolated from man. Two of the Candida species were identified correctly to genus level using API 20C (Auxanogramme), as were three isolates of Geotrichum. For the remaining yeasts tested, API 20C (Auxanogramme) was consistently more reliable than the other systems.

The auxanogram reactions of $T$. glabrata and $C$. krusei, and those for $C$. parakrusei and some strains of $C$. tropicalis, are the same for the seven carbohydrates contained in the Auxodisk. Isolates of $T$. glabrata and $S$. cerevisiae studied could not be correctly identified since neither species is included in the Auxodisk table of reactions.

In addition to the isolates that gave reactions uncharacteristic for any of the species listed by the manufacturers there were 36 occasions when the reactions obtained gave a false-positive identification (Table 3). This was due largely to the failure of one or more reagents to give the expected positive result. Five of the discrepant results obtained with API 20C were due to the failure of $C$. albicans ( 3 isolates) and C. stellatoidea (1 isolate) to grow in the actidione substrate. The yeasts, therefore, appeared to give the reactions of $C$. tropicalis.

Correct identification of three isolates of $C$.

Table 3 Number of yeast strains wrongly identified on the basis of biochemical reaction

\begin{tabular}{lrllll}
\hline Yeast & No. API 20C API 20C & $\begin{array}{c}\text { Auxodisk } \\
\text { Auxano- } \\
\text { gramme }\end{array}$ & Mycotube \\
\hline C. albicans & 21 & 3 & 0 & 0 & 6 \\
C.parapsilosis & 2 & & & & 2 \\
C.pseudotropicalis & 3 & 1 & 2 & 1 \\
C. stellatoidea & 2 & 1 & & $2 \dagger$ & $2 *$ \\
Candida species & 3 & $2 \dagger$ & $2 \dagger$ & $2 \dagger$ & \\
T. glabrata & 7 & & & 3 & 1 \\
C.neoformans & 3 & & & 3 & \\
Geotrichum species & 3 & 1 & & & \\
\hline
\end{tabular}

* 1 Isolate identified as different Candida species † 2 Isolates identified as different Candida species 
neoformans was impossible with Auxodisk because of failure to grow around the cellibiose or raffinose disks. Thus the yeasts gave the reactions of $C$. tropicalis. Two isolates of $C$. stellatoidea gave a positive reaction with sucrose using Auxodisk and therefore gave the reactions of $C$. albicans. Mycotube gave unreliable results for citrate utilisation with $C$. neoformans and C. parapsilosis, the latter giving the reactions of $C$. stellatoidea in consequence. Gas production from glucose and sucrose was difficult to determine with Mycotube. As a result, six isolates of $C$. albicans produced the biochemical reactions of C. stellatoidea, C. krusei, or T. glabrata. The overall results obtained with these four systems are shown in Table 4.

Table 4 Biochemical results obtained from 50 yeast isolates (as a percentage)

\begin{tabular}{|c|c|c|c|c|}
\hline & $A P I 20 C$ & $\begin{array}{l}\text { API } 20 C \\
\text { Auxano- } \\
\text { gramme }\end{array}$ & Auxodisk & Mycotube \\
\hline \multicolumn{5}{|l|}{ Correct identity- } \\
\hline Correct identity- & & & & \\
\hline C. albicans & 76 & 90 & 100 & 71 \\
\hline Correct identity- & & & & \\
\hline other yeasts & 65 & 83 & 24 & 65 \\
\hline Unidentified yeasts & 16 & 10 & 18 & 10 \\
\hline Wrong identity & 16 & 4 & 28 & 24 \\
\hline
\end{tabular}

The four systems varied in their ease of application. Preparation of Auxodisk was uncomplicated provided that care was taken to standardise the inoculum to an absorption of 0.5-0.6 at $450 \mathrm{~nm}$ and a pathwidth of $1 \mathrm{~cm}$. Mycotube required no preliminary preparation, but with many of the drier colonial types the viable inoculum was completely removed from the inoculating wire before it reached the chamber containing glucose. Repeat examination usually produced the same effect. The API 20C systems were more difficult to use. The density of the yeast suspension and the filling of the cupules were critical if accurate and reproducible results were to be obtained. Although final identification using the API 20C (Auxanogramme) system requires 72 hours' incubation, it was found that many of the more common pathogenic yeasts could be reliably identified after 24 or 48 hours' incubation.

\section{Discussion}

The identification of many yeasts is facilitated by their colonial or cellular morphology and characteristics. However, in many laboratories such characterisation is limited to the demonstration of germ tubes and/or chlamydospores by $C$. albicans. Demonstration of biochemical reactions is required to establish or to confirm identity, and this comparative study has been confined to the biochemical reactions of yeasts. If it is to be of value, the information obtained from commercially available kits should be accurate, reliable, reproducible, and unambiguous and should, ideally, provide identification more quickly than the conventional methods.

On biochemical grounds alone the four schemes varied in their efficiency in identifying $C$. albicans from $71 \%$ with Mycotube to $100 \%$ with Auxodisk.

Most laboratories identify $C$. albicans by germ tube production, reserving biochemical investigation for germ tube negative yeasts. The efficiency with which the latter were identified varied from $24 \%$ with Auxodisk to $83 \%$ with API 20C (Auxanogramme). The reliability of Auxodisk with eight tests and Mycotube with 10 tests was not high, due mainly to particular substrates giving falsenegative results consistently. The API 20C systems were better in this respect, and the adverse effect of a single discrepant result was minimised because of the larger number of tests. The omission of $T$. glabrata and $S$. cerevisiae from the Auxodisk table of reactions, coupled with failure of the system to differentiate biochemically $C$. parakrusei from some strains of $C$. tropicalis, is a serious drawback. The API 20C system is capable of identifying many more species than either Auxodisk or Mycotube. The size of the identification tables, however, makes it difficult to use. This problem was solved by the numerical profile of API 20C (Auxanogramme).

The failure of the systems tested to identify the less common Candida species and, to a lesser extent, the Geotrichum species tested is less disturbing than the poor results obtained with $C$. neoformans and the large number of yeasts wrongly identified.

\section{Conclusions}

\section{AUXODISK}

Unsatisfactory substrates, overlap between species listed in the identification table, and omission of pathogenic yeasts from it severely limit the value of the system which can be relied upon to identify only C.albicans.

\section{MYCOTUBE}

This is more reliable than Auxodisk, but the consistent failure of the citrate substrate, the difficulties associated with the determination of gas production and xylose fermentation, and repeated failure of the inoculating wire to seed all the agar compartments are drawbacks.

API 20C

This is significantly better than Auxodisk or Myco- 
tube, although it is more difficult to put up. Cost would probably confine its routine use to yeasts other than $C$. albicans. The complexity of the tables of reactions makes interpretation difficult. The unreliability of the actidione sensitivity test also limits its usefulness.

\section{API 20C (AUXANOGRAMME)}

Many of the problems attendant on the other systems have been resolved by replacing fermentation tests with an increased range of assimilation reactions, although accurate standardisation of the suspension and filling of the cupules are essential. The high percentage of yeasts identified solely on biochemical grounds by this system, and the ease with which the results can be interpreted, commend it for use in the routine laboratory.

We are indebted to $\operatorname{Dr} D$. W. R. MacKenzie, Mycology Reference Laboratory, for 25 of the yeasts studied, and to API Limited, Farnborough, Hants, F. Hoffman-La Roche and Company, Welwyn Garden City, Herts, and Sobioda, 35 Rue Joseph Chanrion, 3800 Grenoble, France, for supplying the identification kits.

\section{References}

Gentles, J. C., and La Touche, C. J. (1969). Yeasts as human and animal pathogens. In The Yeasts, edited by A. H. Rose and J. S. Harrison, Volume 1, pp. 107-182. Academic Press, London.

Hurley, R. (1967). The pathogenic Candida species: a review. Review of Medical and Veterinary Mycology, 6, 159-176.

Lodder, J. (Ed.) (1970). The Yeasts, 2nd edition. North Holland Publishing Company, Amsterdam.

van Uden, N., and Buckley, H. (1970). Candida Berkhout. In The Yeasts, edited by J. Lodder, 2nd edition, pp. 8931087. North Holland Publishing Company, Amsterdam. van der Walt, J. P. (1970). Criteria and methods used in classification. In The Yeasts, edited by J. Lodder, 2nd edition, pp. 34-113. North Holland Publishing Company, Amsterdam.

Requests for reprints to: Dr J. de Louvois, Department of Microbiology, Bernhard Baron Memorial Research Laboratories, Queen Charlotte's Maternity Hospital, Goldhawk Road, London W6 0XG, UK. 